\title{
Intermediate outcomes after the Fontan procedure in the current era
}

\author{
Michael E. Mitchell, MD, ${ }^{a}$ Richard F. Ittenbach, PhD, ${ }^{b}$ J. William Gaynor, MD, ${ }^{c}$ Gil Wernovsky, MD,
} Susan Nicolson, MD, and Thomas L. Spray, MD ${ }^{\mathrm{c}}$

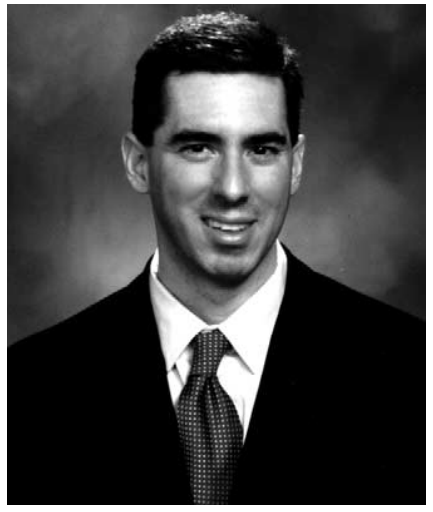

Dr. Mitchell
From the Department of Surgery, Division of Cardiothoracic Surgery, University of Louisville, Louisville, Ky, ${ }^{\text {a }}$ the Biostatistics and Data Management Core, The Children's Hospital of Philadelphia, Philadelphia, $\mathrm{Pa},{ }^{\mathrm{b}}$ the Division of Cardiothoracic Surgery, Children's Hospital of Philadelphia, University of Pennsylvania, Philadelphia, $\mathrm{Pa}^{\mathrm{c}}$ the Division of Pediatric Cardiology and Department of Pediatrics, Children's Hospital of Philadelphia, University of Pennsylvania School of Medicine, Philadelphia, $\mathrm{Pa},{ }^{\mathrm{d}}$ and the Division of Cardiothoracic Anesthesia, Children's Hospital of Philadelphia, University of Pennsylvania, Philadelphia, $\mathrm{Pa}^{\circ}$

Read at the Eighty-fifth Annual Meeting of The American Association for Thoracic Surgery, San Francisco, Calif, April 10-13, 2005.

Received for publication April 12, 2004; revisions received June 8, 2005; accepted for publication August 1, 2005.

Address for reprints: Michael E. Mitchell, MD, University of Louisville, 201 Abraham Flexner Way, Suite 1200, Louisville, KY 40202 (E-mail: mmitchell@ucsamd. com).

J Thorac Cardiovasc Surg 2006;131:172-80

$0022-5223 / \$ 32.00$

Copyright () 2006 by The American Association for Thoracic Surgery

doi:10.1016/j.jtcvs.2005.08.047
Objective: This study was undertaken to investigate the intermediate outcomes after the Fontan operation in the current era.

Methods: A cross-sectional analysis was performed by using data gathered between October 13, 2003, and February 22, 2005, on all 310 survivors of the Fontan procedure between January 1, 1992, and December 31, 1999. Medical records were reviewed, and a customized questionnaire was administered to caregivers. Outcome variables included failure of the Fontan operation (ie, death, takedown of Fontan, or transplantation), number of cardiac-related rehospitalizations, parental assessment of health, school performance, and cardiac functional status.

Results: A total of 332 patients underwent the Fontan procedure during the study period. A lateral tunnel was constructed in 281 (85\%), and an extracardiac Fontan procedure was performed in $51(15 \%)$. A total of $210(63 \%)$ children had undergone previous stage I reconstruction, and 162 (49\%) had received an initial diagnosis of hypoplastic left heart syndrome. There were 310 hospital survivors of the Fontan procedure (93.4\%), with an additional 16 deaths (5.2\%) during follow-up and 1 living heart transplant patient before the cross-sectional period. For initial hospital survivors, Kaplan-Meier estimates of freedom from death or transplantation were 98.0\% (95\% confidence interval, 95.6\%-99.1\%) at 1 year after the Fontan procedure, $94.9 \%(91.6 \%-97.0 \%)$ at 5 years, and $93.9 \%(90.1 \%-96.2 \%)$ at 8 years. Questionnaires were completed for $240(81.9 \%)$ of the 293 available patients. By parental recollection, a total of $130(54.2 \%)$ children required cardiac-related rehospitalization at some point during the follow-up period. At a median follow-up of 8.6 years (range, 4.1-12.8 years), $94.6 \%$ of guardians described their child's overall health as excellent or good, and $5.4 \%$, as fair or poor. School performance was described as above average in $30.2 \%$, average in $39.9 \%$, and below average in $29.8 \%$. With regard to cardiac functional status, $34.2 \%$ responded that their child had no limitations to physical activity, $52.5 \%$ reported a slight limitation, $12.1 \%$ reported a significant limitation, and $1.2 \%$ reported a severe limitation.

Conclusions: Acceptable survival outcomes have been observed at intermediate follow-up of the Fontan operation in this cohort; a significant proportion of patients had hypoplastic left heart syndrome. Although cardiac-related rehospitalization is common, the parents and guardians believed that overall health, school performance, and cardiac functional status were good to excellent for most patients.

$\mathrm{S}$ ince the introduction of the total cavopulmonary anastomosis by Fontan and Baudet more than 30 years ago, preoperative indications, operative techniques, and postoperative management strategies of the Fontan patient have all evolved significantly. Advances in echocardiography and interventional catheterization techniques, along with the increased availability of prostaglandins in recent years, have resulted in significant modifications in the treatment of patients 


\section{Abbreviations and Acronyms \\ CI = confidence interval \\ HLHS = hypoplastic left heart syndrome}

with a functional single ventricle. Furthermore, many of these changes have occurred in the last 15 years, most notably routine interim staging with an interim bidirectional cavopulmonary anastomosis, successful completion of the Fontan procedure for increasingly younger patients, and routine use of baffle fenestration by many centers. However, despite these advances and their potential effect on clinical practice and care, few data exist on intermediate outcomes after current Fontan modifications.

Previously, large cross-sectional studies have reported that hypoplastic left heart syndrome (HLHS) and increasing duration of follow-up are among the strongest predictors of morbidity and failure of the Fontan procedure. ${ }^{1}$ If still valid today, these are particularly troublesome findings given the success of the Norwood procedure and the increased proportion of patients with HLHS now surviving with a Fontan circulation.

The purpose of this study was to examine the intermediateterm survival and functional outcomes of patients with a functional single ventricle who have undergone a Fontan operation at a large-volume center in the current era. The outcome variables assessed included failure of the Fontan operation, rehospitalization, parental assessment of health, school performance, and cardiac functional status.

\section{Patients and Methods \\ Subjects}

A cross-sectional follow-up study was conducted between October 13, 2003, and February 22, 2005, on all 310 survivors of 332 patients who underwent the Fontan procedure between January 6 , 1992, and December 17, 1999, at the Children's Hospital of Philadelphia, a group for which surgical outcomes have been previously reported. ${ }^{2}$ Patients who died or underwent cardiac transplantation were considered to be instances of failed Fontan circulation and were included in the survival analysis, but transplantation survivors were excluded from the intermediate-term functional analyses. Thus, for the questionnaire responders, all patients had Fontan circulation at the time of follow-up.

Fifty patients were not able to be contacted during the crosssectional follow-up period but were known to be alive at some point before the cross-sectional follow-up period. The median time from the Fontan procedure until the last known visit in this group was 0.7 years (range, 5.0 days to 11.0 years). Data from all 310 hospital survivors were included in the survival analysis. Survival information was obtained on 260 patients (83.9\%) within the cross-sectional follow-up period. The median follow-up time was 8.3 years (range, 6.0 days to 12.8 years), and phone interviews with questionnaires were completed with caregivers for 240
(81.9\%) of the 293 survivors of the Fontan procedure who had an intact Fontan circulation at the time of the questionnaire.

\section{Patient Contact and Perioperative Variables}

Medical records including clinic notes and the cardiac surgical database records of all patients from the Children's Hospital of Philadelphia were reviewed, and relevant preoperative and follow-up data were compiled and entered into an electronic database. Patients who were not known to be deceased were contacted by telephone, and an institutional review board-approved customized questionnaire was administered to the caregiver of these patients which addressed parental assessment of health status, school performance, and cardiac functional status. Medical records, preoperative echocardiographic and cardiac catheterization data, and operative notes were reviewed to obtain the perioperative data.

\section{Outcome Measurements}

The following outcome indices were obtained by the customized telephone interview.

Fontan-related rehospitalizations. Parents were asked the number and nature of all rehospitalizations after the Fontan operation. The distribution of responses was then dichotomized into 2 groups: a reference group (no rehospitalizations or 1 Fontan-related rehospitalization) and a comparison group (2 or more Fontanrelated rehospitalizations). Reasons for rehospitalization included surgery, day surgery, catheterizations, visits to the emergency room, and hospital admissions. Fontan-related rehospitalization included any cardiac admission (eg, arrhythmias, catheterizations, or cardiac or thoracic operative procedures); any admission for pleural effusion, protein-losing enteropathy, or surgical wound infection; and any admission to evaluate symptoms otherwise not specified (eg, chest pain, shortness of breath, dizziness, palpitations, nausea, or dehydration) for which a clear alternative diagnosis was not found. Pneumonia was not considered a Fontanrelated admission.

Parental assessment of health performance. Parents were asked to characterize their child's current health status as excellent, good, fair, or poor.

Parental assessment of school performance. Parents were asked to rate their child's school performance relative to the child's peers on a 3-point scale: below average, average, or above average.

Parental assessment of cardiac functional status. Parental assessment of cardiac functional status was accomplished by asking caregivers whether there were any limitations to the child's physical activity; if so, these limitations were specifically identified. Cardiac functional status was then assigned by the single interviewer (M.E.M.).

\section{Statistical Analysis}

Data analysis occurred in 2 distinct phases: a descriptive phase and an inferential phase. Descriptive statistics were first generated for all relevant variables in the data set, with a particular emphasis on patient-related, operative, postoperative, and long-term health care factors hypothesized to have an influence on 5 specific outcomes of interest: failure of the Fontan procedure, Fontan-related rehospitalizations, parental assessment of health status, parental assess- 
TABLE 1. Single-covariate risk factor model values for Fontan failure

\begin{tabular}{|c|c|c|c|}
\hline Risk factor & $\beta$ Coefficient & $\begin{array}{l}\text { Fontan failure, OR } \\
(95 \% \mathrm{Cl})\end{array}$ & $P$ value \\
\hline \multicolumn{4}{|l|}{ Patient-related factors } \\
\hline Age at Fontan & 0.07 & $1.07(1.08-1.16)$ & .05 \\
\hline Anatomic diagnosis* & & & .77 \\
\hline LV-NRGA & & Reference group & \\
\hline LV-TGA & 1.02 & $2.76(0.29-26.57)$ & .38 \\
\hline Heterotaxy & 0.74 & $2.09(0.13-33.44)$ & .60 \\
\hline Single RV & 0.53 & $1.70(0.11-27.17)$ & .71 \\
\hline HLHS & 1.12 & $3.06(0.39-23.69)$ & .28 \\
\hline AV morphology & 0.82 & $2.27(0.65-7.94)$ & .20 \\
\hline $\mathrm{AV}$ valve regurgitation & 0.05 & $1.05(0.14-7.92)$ & .96 \\
\hline Heterotaxy $(\mathrm{Y} / \mathrm{N})$ & -0.22 & $0.80(0.11-6.06)$ & .83 \\
\hline Initial palliationt & & & .54 \\
\hline None & & Reference group & \\
\hline BAS/shunt & -0.22 & $0.80(0.07-8.86)$ & .86 \\
\hline Pulmonary artery band & 1.03 & $2.79(0.29-26.92)$ & .37 \\
\hline Stage I & 0.48 & $1.61(0.21-12.41)$ & .65 \\
\hline Stage I (Y/N) & 0.20 & $1.22(0.46-3.26)$ & .69 \\
\hline Interim staging $\dagger$ & & Noncalculable & \\
\hline \multicolumn{4}{|l|}{ Operative factors } \\
\hline Type of Fontan (LT/EC) & 0.70 & $2.01(0.64-6.30)$ & .23 \\
\hline Year of Fontan & -0.01 & $0.99(0.80-1.22)$ & .90 \\
\hline Fenestration & -0.11 & $0.89(0.20-3.91)$ & .88 \\
\hline Additional procedures & & Noncalculable & \\
\hline CPB Time & 0.01 & $1.01(0.99-1.02)$ & .22 \\
\hline Crossclamp time & 0.03 & $1.03(1.00-1.05)$ & $.02 \ddagger$ \\
\hline DHCA time & 0.02 & $1.02(0.99-1.05)$ & .16 \\
\hline Total support time & 0.01 & $1.01(1.00-1.02)$ & .13 \\
\hline Modified ultrafiltration (Y/N) & -0.82 & $0.44(0.14-1.38)$ & .16 \\
\hline \multicolumn{4}{|l|}{ Postoperative factors } \\
\hline Duration of ventilation & $<0.01$ & $1.00(1.00-1.00)$ & .44 \\
\hline Duration of chest tube & 0.28 & $1.33(1.08-1.63)$ & $<.01$ \\
\hline Duration of ICU stay & 0.01 & $1.01(0.99-1.03)$ & .25 \\
\hline Duration of hospital stay & $<0.01$ & $1.00(0.99-1.01)$ & .48 \\
\hline \multicolumn{4}{|l|}{ Long-term health care factors } \\
\hline Number of medications & 0.18 & $1.19(0.41-3.46)$ & .74 \\
\hline Number of hospitalizations & -0.11 & $0.89(0.23-3.42)$ & .87 \\
\hline Pacemaker & 1.54 & $4.65(0.29-74.83)$ & .28 \\
\hline
\end{tabular}

$O R$, Odds ratio; $C l$, confidence interval; $L V$-NRGA, left ventricle with normally related great arteries; $L V$-TGA, left ventricle with transposed or malposed great arteries; $R V$, right ventricle; $H L H S$, hypoplastic left heart syndrome; $A V$, atrioventricular; $B A S$, balloon atrial septostomy; $E C$, extracardiac; $L T$, lateral tunnel; $C P B$, cardiopulmonary bypass; $D H C A$, deep hypothermia and circulatory arrest; $I C U$, intensive care unit. *Dummy coded variable with classes listed below the variable name. $†$ The interim staging variable had insufficient variability to yield stable Cox regression model solutions. $\ddagger$ Bolded terms denote statistically significant contributors to a multivariable model after adjustment for the year of the Fontan procedure.

ment of school performance, and parental assessment of cardiac functional status. Four of the 5 outcomes were dichotomous: failure of the Fontan procedure, number of Fontan-related rehospitalizations (no rehospitalizations or 1 hospitalization vs $\geq 2$ hospitalizations), parental assessment of health status (excellent vs good, fair, or poor), and parental assessment of cardiac functional status (excellent or good vs fair or poor). The fifth outcome, parental assessment of school performance, was polytomous (excellent, good/fair, or poor). In addition, a Kaplan-Meier curve estimating freedom from death or transplantation was constructed for the entire sample of hospital survivors, and freedom from death or transplantation probabilities were computed, complete with 95\% confidence intervals (CIs). This was a freedom from Fontan failure survival curve, with time 0 defined as the date of the Fontan procedure and with failure defined as either the date of death or the date of heart transplantation, when known, or patients were withdrawn alive at the time of the last known contact.

In the second phase, the inferential phase, 24 different singlecovariate logistic regression models were specified and tested for each of the 5 aforementioned outcomes by using a Cox propor- 
TABLE 2. Single-covariate risk factor model values for parental assessment of health, parental assessment of cardiac functioning, and rehospitalization

\begin{tabular}{|c|c|c|c|c|c|c|c|c|c|}
\hline \multirow[b]{2}{*}{ Risk factor } & \multicolumn{3}{|c|}{ Rehospitalization } & \multicolumn{3}{|c|}{ Parental assessment of health } & \multicolumn{3}{|c|}{$\begin{array}{c}\text { Parental assessment of cardiac } \\
\text { functioning }\end{array}$} \\
\hline & $\begin{array}{c}\boldsymbol{\beta} \\
\text { Coefficient }\end{array}$ & OR (95\% Cl) & $\begin{array}{c}P \\
\text { value }\end{array}$ & $\begin{array}{c}\beta \\
\text { Coefficient }\end{array}$ & OR $(95 \% \mathrm{Cl})$ & $\begin{array}{c}P \\
\text { value }\end{array}$ & $\begin{array}{c}\boldsymbol{\beta} \\
\text { Coefficient }\end{array}$ & OR $(95 \% \mathrm{Cl})$ & $\begin{array}{c}P \\
\text { value }\end{array}$ \\
\hline \multicolumn{10}{|l|}{ Patient-related factors } \\
\hline Age at Fontan & 0.05 & $1.05(0.96-1.15)$ & .25 & 0.22 & $1.24(1.05-1.46)$ & $.01 \dagger$ & 0.05 & $1.05(0.95-1.16)$ & .30 \\
\hline Anatomic diagnosis* & & & .18 & & & .74 & & & .17 \\
\hline LV-NRGA & \multicolumn{3}{|c|}{ Reference group } & \multicolumn{3}{|c|}{ Reference group } & \multicolumn{3}{|c|}{ Reference group } \\
\hline LV-TGA & 1.05 & $2.86(0.99-8.25)$ & .05 & -0.16 & $0.85(0.33-2.15)$ & .73 & -0.55 & $0.58(0.18-1.84)$ & .35 \\
\hline Heterotaxy & 0.13 & $1.14(0.28-4.57)$ & .85 & 0.06 & $1.06(0.34-3.30)$ & .92 & -1.02 & $0.36(0.07-1.89)$ & .23 \\
\hline Single RV & 0.62 & $1.87(0.55-6.33)$ & .32 & -0.12 & $0.88(0.30-2.57)$ & .82 & -0.44 & $0.64(0.17-2.41)$ & .51 \\
\hline HLHS & 0.13 & $1.14(0.45-2.91)$ & .78 & -0.43 & $0.65(0.30-1.40)$ & .27 & -1.21 & $0.30(0.11-0.79)$ & .02 \\
\hline AV morphology & -0.10 & $0.90(0.32-2.58)$ & .85 & 0.21 & $1.23(0.50-3.02)$ & .65 & -0.41 & $0.66(0.15-2.99)$ & .59 \\
\hline$A V$ valve regurgitation & -1.24 & $0.29(0.04-2.31)$ & .24 & 0.09 & $1.10(0.32-3.70)$ & .88 & & Noncalculable & \\
\hline Heterotaxy $(\mathrm{Y} / \mathrm{N})$ & -0.20 & $0.82(0.26-2.60)$ & .74 & 0.31 & $1.36(0.52-3.56)$ & .53 & -0.22 & $0.80(0.18-3.66)$ & .77 \\
\hline Initial palliation* & & & .20 & & & $<.01$ & & & .36 \\
\hline None & \multicolumn{3}{|c|}{ Reference group } & \multicolumn{3}{|c|}{ Reference group } & \multicolumn{3}{|c|}{ Reference group } \\
\hline BAS/shunt & 0.69 & $2.00(0.51-7.90)$ & .32 & 1.16 & $3.20(1.02-10.02)$ & .05 & 0.36 & $1.43(0.35-5.81)$ & .62 \\
\hline Pulmonary artery band & 1.50 & $4.50(1.01-20.11)$ & .05 & 2.08 & $8.00(2.01-31.80)$ & $<.01$ & 0.34 & $1.41(0.27-7.26)$ & .68 \\
\hline Stage I & 0.68 & $1.98(0.55-7.12)$ & .30 & 0.72 & $2.05(0.71-5.90)$ & .18 & -0.38 & $0.69(0.18-2.61)$ & .58 \\
\hline Stage I (Y/N) & -0.09 & $0.91(0.50-1.65)$ & .76 & -0.40 & $0.67(0.40-1.13)$ & .13 & -0.66 & $0.52(0.24-1.10)$ & .09 \\
\hline Interim staging & & Noncalculable & & & Noncalculable & & & Noncalculable & \\
\hline \multicolumn{10}{|l|}{ Operative factors } \\
\hline Type of Fontan (LT/EC) & -0.86 & $0.42(0.16-1.14)$ & .09 & -0.12 & $0.89(0.44-1.82)$ & .75 & -0.64 & $0.53(0.15-1.84)$ & .32 \\
\hline Year of Fontan & -0.11 & $0.89(0.79-1.01)$ & .08 & 0.03 & $1.03(0.92-1.14)$ & .63 & -0.06 & $0-1.10)$ & .45 \\
\hline Fenestration & -0.27 & $0.76(0.30-1.95)$ & .57 & -0.22 & $0.80(0.34-1.90)$ & .62 & 0.03 & $1.03(0.29-3.68)$ & .97 \\
\hline Additional procedures & -0.45 & $0.64(0.13-3.03)$ & .57 & 0.88 & $2.42(0.69-8.51)$ & .17 & -0.45 & $0.64(0.08-5.16)$ & .67 \\
\hline CPB time & 0.01 & $1.01(1.00-1.02)$ & .22 & $<0.01$ & $1.00(0.99-1.01)$ & .76 & $<0.01$ & $1.00(0.98-1.02)$ & .79 \\
\hline Crossclamp time & 0.02 & $1.02(0.99-1.04)$ & .16 & $<0.01$ & $1.00(0.98-1.02)$ & .69 & -0.01 & $0.99(0.96-1.02)$ & .50 \\
\hline DHCA time & 0.03 & $1.03(1.00-1.05)$ & .02 & $<0.01$ & $1.00(0.98-1.02)$ & .90 & 0.01 & $1.01(0.98-1.04)$ & .58 \\
\hline Total support time & 0.01 & $1.01(1.00-1.02)$ & .05 & $<0.01$ & $1.00(0.99-1.01)$ & .85 & $<0.01$ & $1.00(0.99-1.01)$ & .98 \\
\hline Modified ultrafiltration (Y/N) & -0.39 & $0.68(0.38-1.22)$ & .20 & 0.36 & $1.43(0.85-2.38)$ & .17 & -0.07 & $0.93(0.44-1.97)$ & .86 \\
\hline \multicolumn{10}{|l|}{ Postoperative factors } \\
\hline Duration of ventilation & 0.01 & $1.01(1.00-1.02)$ & .22 & 0.01 & $1.01(0.99-1.02)$ & .36 & $<0.01$ & $1.00(1.00-1.01)$ & .28 \\
\hline Duration of chest tube & 0.27 & $1.31(1.00-1.73)$ & .05 & 0.05 & $1.05(0.82-1.35)$ & .70 & 0.16 & $1.18(0.88-1.58)$ & .27 \\
\hline Duration of ICU stay & 0.01 & $1.01(0.99-1.04)$ & .31 & -0.02 & $0.98(0.95-1.02)$ & .32 & $<0.01$ & $1.00(0.98-1.03)$ & .69 \\
\hline Duration of hospital stay & $<0.01$ & $1.00(1.00-1.01)$ & .32 & $<0.01$ & $1.00(0.99-1.01)$ & .78 & $<0.01$ & $1.00(0.98-1.01)$ & .83 \\
\hline \multicolumn{10}{|l|}{ Long-term health care factors } \\
\hline Number of medications & 0.62 & $1.87(1.40-2.49)$ & $<.01$ & 0.31 & $1.37(1.07-1.74)$ & .01 & 0.19 & $1.21(0.88-1.67)$ & .25 \\
\hline Number of hospitalizations & & Noncalculable & & 0.33 & $1.39(1.10-1.76)$ & $<.01$ & 0.09 & $1.09(0.96-1.24)$ & .17 \\
\hline Pacemaker & 2.71 & $15.05(5.70-39.71)$ & $<.01$ & 0.74 & $2.11(0.93-4.76)$ & .07 & 1.20 & $3.32(1.31-8.39)$ & .01 \\
\hline
\end{tabular}

$O R$, Odds ratio; $C l$, confidence interval; $L V$-NRGA, left ventricle with normally related great arteries; $L V$ - TGA, left ventricle with transposed or malposed great arteries; $R V$, right ventricle; $H L H S$, hypoplastic left heart syndrome; $A V$, atrioventricular; $B A S$, balloon atrial septostomy; $E C$, extracardiac; $L T$, lateral tunnel; $C P B$, cardiopulmonary bypass; $D H C A$, deep hypothermia and circulatory arrest; $I C U$, intensive care unit. *Dummy coded variable with classes listed below the variable name. $\dagger$ Bolded terms denote statistically significant contributors to a multivariable model after adjustment for the year of the Fontan procedure.

tional hazards regression model for the survival data, simple logistic regression for the dichotomous outcomes, and multinomial logistic regression for the categorical outcome (see Tables 1 and 2 for a listing of all covariates used). Dummy codes were initially used for 3 categorical covariates: anatomic diagnosis, initial palliation, and interim staging with cavopulmonary connection. Multiple covariate models were then specified and tested by using single-covariate models with Wald statistic $P$ values $<.15$ as candidates for inclusion in the larger models. Because of recent advances in both operative and postoperative care between 1992 and 1999, all multiple-covariate models were adjusted for the year of the Fontan procedure. Type I error rates were held constant at the $\alpha=.05$ level for all analyses. All data were analyzed with Stata 8.0 (Stata Corp, College Station, Tex). 


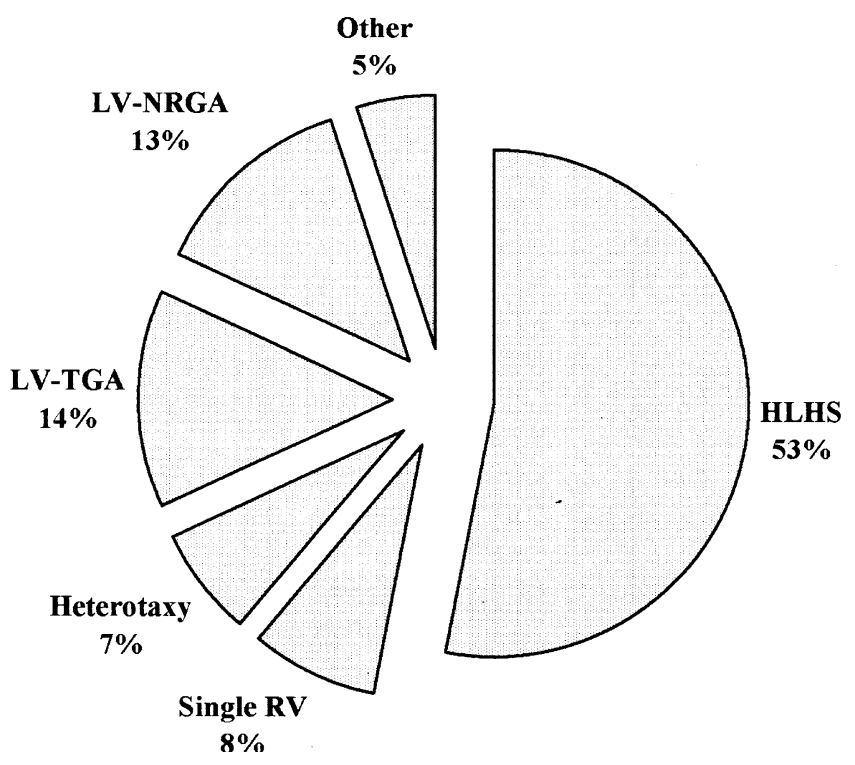

Figure 1. Anatomic subtypes. LV-NRGA, Left ventricle with normally related great arteries; $L V$-TGA, left ventricle with transposed or malposed great arteries; RV, right ventricle; HLHS, hypoplastic left heart syndrome. Other includes indeterminate RV or ventricle of unknown pathology.

\section{Results}

\section{Study Population}

Of the 332 patients undergoing the Fontan procedure at our institution between January 1, 1992, and December 31, 1999, 310 (93.4\%) patients survived the early postoperative period. All survivors had Fontan circulation intact at the time of discharge. The Fontan operation involved a lateral tunnel in $262(84.5 \%)$ patients and an extracardiac conduit in $48(15.5 \%)$. At the time of the Fontan procedure, 279 $(90.0 \%)$ patients underwent fenestration, and $31(10.0 \%)$ were nonfenestrated. There was a common atrioventricular valve in $28(9.0 \%)$. Data on the severity of atrioventricular valve regurgitation at the time of the Fontan procedure were available on $308(99.4 \%)$ of 310 patients; regurgitation was absent in 196 (63.6\%), mild in 93 (30.2\%), moderate in 17 $(5.5 \%)$, and severe in $2(0.6 \%)$. HLHS was the preoperative diagnosis in $164(53 \%)$ children, single right ventricle (not HLHS) was present in 25 (8\%), heterotaxy was present in $23(7 \%)$, single left ventricle with normally related great arteries was present in $41(13 \%)$, single left ventricle with transposed great arteries was present in 43 (14\%), and other diagnoses were present in 14 (5\%) (Figure 1).

The overall freedom from death or transplantation rate was $94.8 \%$. A total of 18 late treatment failures were observed; 7 of these 18 patients underwent transplantation (2 survivors), whereas 11 of the 18 died without transplantation. All other patients surveyed continue with functioning

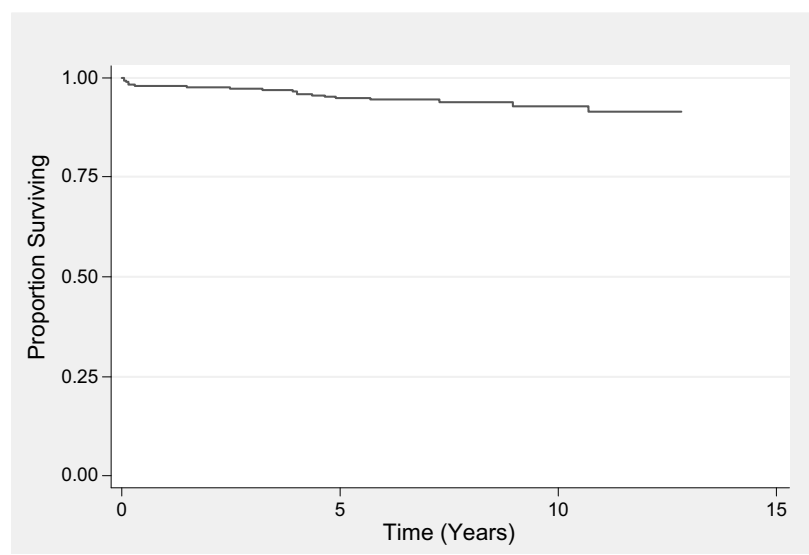
$\begin{array}{lll}5 \text { yr Freedom from Death or Transplant: } & 94.9 \%(91.6-97.0 \%) & \text { Risk Set }=230 \\ 10 \text { yr Freedom from Death or Transplant: } & 93.0 \%(88.8 \%-95.7 \%) & \text { Risk Set }=78\end{array}$

Figure 2. Kaplan-Meier estimate of freedom from death or transplantation.

Fontan circulations; there were no Fontan takedowns. Preoperative variables of late Fontan failures included initial diagnosis of left ventricle with normally related great arteries in 1, left ventricle with transposition of the great arteries in 3 , heterotaxy syndrome in 1 , single right ventricle (single RV) in 1, HLHS in 11, and other in 1.

Of the 18 late treatment failures, $14(78 \%)$ were lateral tunnel Fontans, and $4(22 \%)$ were extracardiac. Sixteen $(89 \%)$ patients underwent some form of fenestration at the time of the Fontan procedure, whereas $2(11 \%)$ did not. In our analysis, there was no difference in the preoperative or operative variables between those whose Fontan procedures failed and those who did not experience treatment failure.

Survival models were constructed for the entire cohort; these models treated transplantation as death at the time of the transplantation. In both single- and multiple-covariate models, factors related to Fontan failure were limited to an increasing duration of crossclamp time during the Fontan procedure $(P=.04)$ and duration of chest tube drainage after the Fontan operation $(P=.02)$. Stage I reconstruction, anatomic diagnosis, duration of deep hypothermic circulatory arrest at the time of the Fontan procedure, and the presence of atrioventricular valve regurgitation at the time of the Fontan procedure were not significant predictors of late failure of Fontan circulation (Table 1). Kaplan-Meier estimates of freedom from death or transplantation for the cohort were as follows: 1 year, 98.0\% (95\% CI, 95.6\%99.1\%); 5 years, $94.9 \%$ (95\% CI, 91.6\%-97.0\%); and 8 years, 93.9\% (95\% CI, 90.1\%-96.2\%) (Figure 2).

Telephone questionnaires were completed in 240 patients. Of the 240 caregivers who completed telephone questionnaires, 50 (20.8\%) were men, and 190 (79.2\%) 


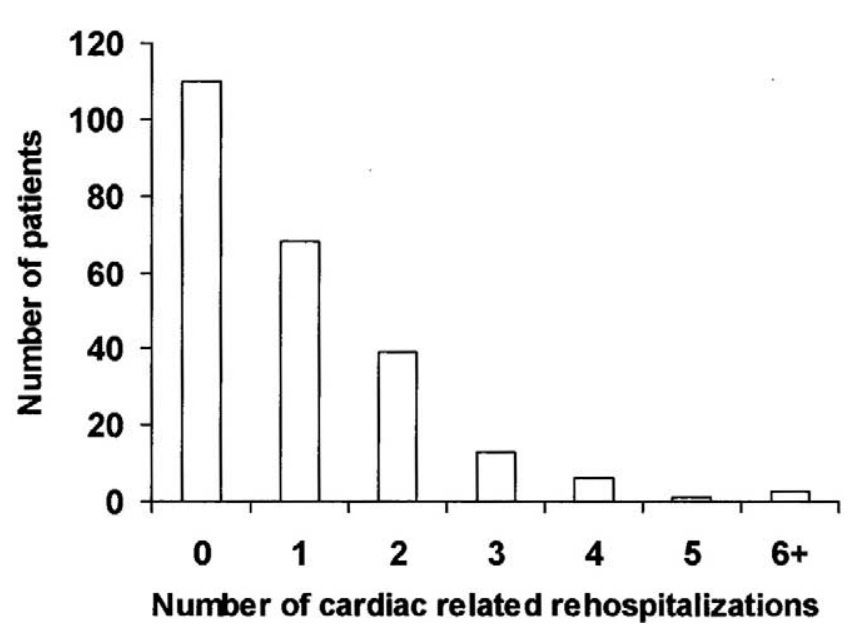

Figure 3. Number of Fontan-related rehospitalizations per patient.

were women. There were no significant differences in operative or perioperative variables between the group with completed questionnaire data and those without completed questionnaires.

\section{Number of Rehospitalizations}

By parental recollection, of the 240 patients with complete questionnaire data, $130(54.2 \%)$ required rehospitalization for a cardiac-related issue during the follow-up period (Figure 3). No cardiac-related rehospitalization was required in the follow-up period in 110 patients (45.8\%). Cardiacrelated rehospitalization was required 1 or 2 times in 107 patients (44.6\%) and 3 or more times in 23 patients (9.6\%). Results from the univariate models are listed in Table 2. Significant risks for multiple cardiac-related rehospitalizations from the multivariable models include total support time $(P<.01)$ at the time of the Fontan procedure and the requirement for a pacemaker after the Fontan procedure $(P<.01)$, with a trend toward significance for those who underwent lateral tunnel Fontan $(P=.062)$.

Single-covariate models were constructed to assess predictors of poor outcome at intermediate follow-up after the Fontan procedure as assessed by parents. These models addressed 3 broad categories: general health, school performance, and functional status (Tables 2 and 3).

\section{Parental Assessment of Health}

Despite a large number of rehospitalizations, most caregivers-138 (57.1\%) — described their child's current health as excellent, and 90 (37.5\%) described it as good; 11 (4.6\%) rated their child's current health as fair, and $2(0.8 \%)$ rated it as poor. Results from the single-covariate models are listed in Table 2. In a multivariable covariate model of parental assessment of health, older age at the time of the Fontan procedure $(P=.02)$, initial palliation with a pulmo- nary artery band $(P=.01)$, and number of cardiac rehospitalizations $(P=.02)$ were associated with fair or poor parental assessment of health. Before stage I reconstruction, the presence of atrioventricular valve regurgitation at the time of the Fontan procedure, the duration of cardiopulmonary bypass, aortic crossclamp, and deep hypothermic circulatory arrest during the Fontan procedure were not associated with parental assessment of health.

\section{Parental Assessment of Cardiac Functional Status}

Using parental assessment of limitations to physical activity by phone interview, a single examiner (M.E.M.) classified the survivors into New York Heart Association functional groups. New York Heart Association functional class I or II was present in $206(86.7 \%)$ children, and $32(13.3 \%)$ were in class III or IV. A single-covariate model was constructed to assess associations with parental assessment of cardiac functional status. These results are listed in Table 2. In a multivariable model, only the requirement for a pacemaker after the Fontan procedure $(P=.02)$ was significantly associated with lower parental assessment of cardiac functional status.

\section{Parental Assessment of School Performance}

Parents were asked to rate their child's performance in school on a 3-point scale: below average, average, or above average. A total of 72 (30.2\%) caregivers rated their child's performance as below average, whereas 95 (39.9\%) rated their children's performance as average, and 71 (29.8\%) rated it as above average. Results from the single-variable model are shown in Table 3. In a multivariable model, there were no significant predictors for poor school performance. Anatomic diagnosis and operative support parameters, including duration of deep hypothermic circulatory arrest, were not associated with parental assessment of school performance.

\section{Discussion}

This cross-sectional follow-up study of all 310 survivors of the Fontan procedure between the years 1992 and 1999 at our institution examined intermediate-term failure rates, the frequency of rehospitalization, medication use, and parental assessment of performance across 3 broad categories: general health, cardiac functional status, and school performance. Although rehospitalization was quite common (occurring in more than half of the survivors, with a median duration of follow-up of just over 8 years), freedom from death or transplantation rates were acceptable, and parental assessments of health, cardiac function, and school performance were good to excellent for most patients.

Operative, perioperative, and postoperative management of children with a functional single ventricle has evolved considerably since the introduction of the Fontan procedure 
TABLE 3. Single-covariate risk factor model values for parental assessment of school performance

\begin{tabular}{|c|c|c|c|c|c|c|c|}
\hline \multirow[b]{2}{*}{ Risk factor } & \multicolumn{3}{|c|}{$\begin{array}{l}\text { Parental assessment of school performance: } \\
\text { good/fair vs poor }\end{array}$} & \multicolumn{3}{|c|}{$\begin{array}{l}\text { Parental assessment of school performance: } \\
\text { excellent vs poor }\end{array}$} & \multirow{2}{*}{$\begin{array}{l}\text { Multinomial } \\
P \text { value }\end{array}$} \\
\hline & $\beta$ Coefficient & RR (95\% CI) & $P$ value & $\beta$ Coefficient & RR (95\% CI) & $P$ value & \\
\hline \multicolumn{8}{|l|}{ Patient-related factors } \\
\hline Age at Fontan & -0.03 & $0.97(0.86-1.09)$ & .64 & -0.14 & $0.86(0.72-1.04)$ & .13 & .22 \\
\hline \multicolumn{8}{|l|}{ Anatomic diagnosis* } \\
\hline LV-NRGA & \multicolumn{3}{|c|}{ Reference group } & \multicolumn{3}{|c|}{ Reference group } & .15 \\
\hline LV-TGA & -0.77 & $0.46(0.14-1.47)$ & .19 & 0.61 & $1.85(0.56-6.13)$ & .32 & \\
\hline Heterotaxy & -0.44 & $0.64(0.17-2.41)$ & .51 & 0.20 & $1.22(0.28-5.37)$ & .79 & \\
\hline Single RV & 0.69 & $2.00(0.44-9.18)$ & .37 & 1.74 & $5.71(1.16-28.07)$ & .03 & \\
\hline HLHS & 0.11 & $1.11(0.47-2.64)$ & .81 & 0.42 & $1.52(0.53-4.34)$ & .44 & \\
\hline AV morphology & 0.01 & $1.01(0.33-3.06)$ & .98 & 0.18 & $1.20(0.38-3.77)$ & .75 & .94 \\
\hline$A V$ valve regurgitation & 0.44 & $1.56(0.28-8.74)$ & .62 & 0.99 & $2.69(0.50-14.36)$ & .25 & .46 \\
\hline Heterotaxy $(\mathrm{Y} / \mathrm{N})$ & -0.47 & $0.63(0.20-1.95)$ & .42 & -0.35 & $0.70(0.21-2.33)$ & .56 & .71 \\
\hline Initial palliation & & & & & & & .24 \\
\hline None & \multicolumn{3}{|c|}{ Reference group } & \multicolumn{3}{|c|}{ Reference group } & \\
\hline BAS/shunt & -1.35 & $0.26(0.05-1.36)$ & .11 & -1.93 & $0.14(0.03-0.77)$ & .02 & \\
\hline Pulmonary artery band & -1.79 & $0.17(0.03-1.07)$ & .06 & -2.08 & $0.12(0.02-0.82)$ & .03 & \\
\hline Stage I & -1.21 & $0.30(0.06-1.45)$ & .13 & -1.63 & $0.20(0.04-0.94)$ & .04 & \\
\hline Stage I (Y/N) & 0.04 & $1.04(0.56-1.96)$ & .90 & -0.02 & $0.98(0.50-1.91)$ & .95 & .98 \\
\hline Interim staging $\dagger$ & & Noncalculable & & & Noncalculable & & \\
\hline \multicolumn{8}{|l|}{ Operative factors } \\
\hline Type of Fontan (LT/EC) & 0.63 & $1.88(0.73-4.85)$ & .19 & 0.82 & $2.28(0.86-6.04)$ & .10 & .21 \\
\hline Year of Fontan & 0.07 & $1.07(0.94-1.22)$ & .29 & 0.12 & $1.13(0.98-1.30)$ & .08 & .21 \\
\hline Fenestration & 0.16 & $1.17(0.40-3.39)$ & .77 & -0.16 & $0.85(0.29-2.48)$ & .76 & .83 \\
\hline Additional procedures & -0.29 & $0.75(0.18-3.09)$ & .69 & -0.29 & $0.75(0.16-3.48)$ & .71 & .90 \\
\hline CPB time & $<0.01$ & $1.00(0.99-1.01)$ & .87 & $<0.01$ & $1.00(0.98-1.01)$ & .74 & .87 \\
\hline Crossclamp time & -0.01 & $0.99(0.97-1.02)$ & .49 & -0.01 & $0.99(0.96-1.01)$ & .34 & .61 \\
\hline DHCA time & -0.01 & $0.99(0.97-1.02)$ & .50 & -0.02 & $0.98(0.95-1.01)$ & .17 & .39 \\
\hline Total support time & $<0.01$ & $1.00(0.99-1.01)$ & .88 & $<0.01$ & $0.99(0.98-1.01)$ & .38 & .64 \\
\hline Modified ultrafiltration (Y/N) & 0.27 & $1.31(0.71-2.44)$ & .39 & 0.53 & $1.71(0.88-3.31)$ & .11 & .28 \\
\hline \multicolumn{8}{|l|}{ Postoperative factors } \\
\hline Duration of ventilation & $<0.01$ & $1.00(0.99-1.00)$ & .44 & -0.02 & $0.98(0.96-1.01)$ & .15 & .08 \\
\hline Duration of chest tube & -0.14 & $0.87(0.66-1.15)$ & .32 & -0.66 & $0.52(0.30-0.89)$ & .02 & .02 \\
\hline Duration of ICU stay & -0.02 & $0.98(0.94-1.02)$ & .38 & $<0.01$ & $1.00(0.98-1.03)$ & .67 & .37 \\
\hline Duration of hospital stay & $<0.01$ & $0.99(0.98-1.00)$ & .36 & $<0.01$ & $1.00(0.99-1.01)$ & .82 & .46 \\
\hline \multicolumn{8}{|l|}{ Long-term health care factors } \\
\hline Number of medications & 0.04 & $1.04(0.79-1.37)$ & .76 & -0.18 & $0.83(0.61-1.13)$ & .25 & .28 \\
\hline Number of hospitalizations & 0.03 & $1.03(0.90-1.18)$ & .64 & -0.22 & $0.80(0.60-1.06)$ & .12 & .10 \\
\hline Pacemaker & -0.21 & $0.81(0.32-2.03)$ & .66 & -0.76 & $0.47(0.15-1.45)$ & .19 & .39 \\
\hline
\end{tabular}

No best-fitting multiple-covariate model could be obtained by using the variables presented here. $R R$, Risk ratio; $C l$, confidence interval; $L V$ - $N R G A$, left ventricle with normally related great arteries; $L V$-TGA, left ventricle with transposed or malposed great arteries; $R V$, right ventricle; $H L H S$, hypoplastic left heart syndrome; $A V$, atrioventricular; $B A S$, balloon atrial septostomy; $E C$, extracardiac; $L T$, lateral tunnel; $C P B$, cardiopulmonary bypass; $D H C A$, deep hypothermia and circulatory arrest; $I C U$, intensive care unit. *Dummy coded variable with classes listed below the variable name. $†$ The interim staging variable had insufficient variability to yield stable multinomial logistic regression solutions.

more than 30 years ago. Improved survival with institutional experience and evolution of surgical techniques since the introduction of the Fontan procedure has been demonstrated by several large studies. ${ }^{1,3-5}$ Controversy remains regarding the optimal type of Fontan reconstruction and whether routine use of fenestration is necessary in all patients. Most reports have found little early difference in mortality when comparing lateral tunnel with extracardiac reconstruction, although there is increasing evidence that routine baffle fenestration decreases postoperative morbidity and the length of hospital stay. ${ }^{6-8}$ With hospital mortality and morbidity continuing to decrease, the effects of the newer Fontan modifications will need to be judged according to their effects on longer-term outcomes. However, mid-term data regarding survival and the functional outcomes of these most recent modifications are limited. ${ }^{6,8}$ 
Our study reports parental assessment of health performance, cardiac functional status, and school performance of 240 survivors of the Fontan procedure between January 1992 and December 1999. In our initial article, ${ }^{9}$ we demonstrated that despite a patient population composed largely of patients with HLHS or variants thereof, mortality has decreased dramatically in recent years, as has morbidity. Indeed, HLHS was not a risk factor for early mortality after the Fontan procedure. ${ }^{2}$ In this study, we similarly found that patient-related demographic variables did not predict poor outcomes in parental assessment of health performance, cardiac functional status, or school performance.

Duration of chest tube drainage and crossclamp time were found to be predictors of failure of the Fontan procedure in both single-variable and multivariable models at intermediate follow-up in this study, but they were not found to be related to early mortality in the previous study of this cohort. ${ }^{2}$ Although it may be the case that these are markers for more severe cardiac pathology, this cannot be determined in the current analysis.

Neurocognitive outcomes after the Fontan procedure have been shown to be in the normal range for most patients, but group data are lower than expected. Most studies have focused on cognitive testing with IQ and achievement testing, ${ }^{10,11}$ but there is growing evidence that behavioral, fine motor, and attention difficulties may play a larger role in school difficulties. ${ }^{12}$ In this study, a significant proportion of parents (30\%) rated their child's performance in school as below average. In contrast to the report from Wernovsky and colleagues, ${ }^{11}$ underlying anatomy and surgical support techniques were not related to the parental assessment of school performance. In that study, there were few patients with HLHS, and objective testing was limited to cognitive and achievement testing.

This study has several important limitations. Although the study was cross-sectional, with only $82 \%$ of the surviving cohort completing the telephone questionnaire, there was no difference in patient- or procedure-related variables between the groups who did and did not respond. This study is based on qualitative parental assessment of performance. Qualitative parental assessment data may not compare to physiological quantitative studies, such as exercise or IQ testing. This questionnaire has not been validated as an instrument; the use of a validated questionnaire may have resulted in different results, and, certainly, correlation with quantitative tests such as exercise or IQ testing would be informative. Although this study represents a large cohort with a median follow-up time of 8 years, this data may not be predictive of longer-term outcome. In this study design, we could not account for interventional or spontaneous closure of a fenestration. Finally, the study may have inadequate power to detect relationships of predictor variables, for example, the duration of cardiopulmonary bypass and functional outcome.
In conclusion, at a median follow-up of 8 years, survival with the current modifications of the Fontan operation is acceptable. Overall functional outcome was rated to be good or excellent by caregivers in the 3 areas of general health, cardiac functional status, and school performance. We could not determine a difference in survival or functional outcomes based on most patient- or procedure-related variables, including ventricular morphology. It is important to note that postoperative morbidities (duration of chest tube drainage and the need for permanent pacing) are related to suboptimal findings at midterm follow-up, and strategies to minimize postoperative complications are critical for improving longer-term health-related quality of life. Although most parents and guardians believe that overall functional outcomes are acceptable, objective correlations are necessary. To address these considerations, objective functional, electrophysiological, and neurodevelopmental testing is currently being planned in this cohort of patients, as is continued, comprehensive follow-up of ongoing surgical modifications.

\section{References}

1. Gentles TL, Mayer JE Jr, Gauvreau K, Newburger JW, Lock JE, Kupferschmid JP, et al. Fontan operation in five hundred consecutive patients: factors influencing early and late outcome. $J$ Thorac Cardiovasc Surg. 1997;114:376-91.

2. Gaynor JW, Bridges ND, Cohen MI, Mahle WT, Decampli WM, Steven JM, et al. Predictors of outcome after the Fontan operation: is hypoplastic left heart syndrome still a risk factor? J Thorac Cardiovasc Surg. 2002;123:237-45.

3. Gentles TL, Gauvreau K, Mayer JE Jr, Fishberger SB, Burnett J, Colan $\mathrm{SD}$, et al. Functional outcome after the Fontan operation: factors influencing late morbidity. J Thorac Cardiovasc Surg. 1997;114:392403; discussion 404-5.

4. Bridges ND. Early and medium-term outcomes after the fenestrated Fontan operation. Adv Card Surg. 1999;11:221-31.

5. Bando K, Turrentine MW, Park HJ, Sharp TG, Scavo V, Brown JW. Evolution of the Fontan procedure in a single center. Ann Thorac Surg. 2000;69:1873-9.

6. Azakie A, McCrindle BW, Van Arsdell G, Benson LN, Coles J, Hamilton R, et al. Extracardiac conduit versus lateral tunnel cavopulmonary connections at a single institution: impact on outcomes. J Thorac Cardiovasc Surg. 2001;122:1219-28.

7. Kumar SP, Rubinstein CS, Simsic JM, Taylor AB, Saul JP, Bradley SM. Lateral tunnel versus extracardiac conduit Fontan procedure: a concurrent comparison. Ann Thorac Surg. 2003;76:1389-96; discussion 1396-7.

8. Lemler MS, Scott WA, Leonard SR, Stromberg D, Ramaciotti C. Fenestration improves clinical outcome of the Fontan procedure: a prospective, randomized study. Circulation. 2002;105:207-12.

9. Cohen MI, Bridges ND, Gaynor JW, Hoffman TM, Wernovsky G, Vetter VL, et al. Modifications to the cavopulmonary anastomosis do not eliminate early sinus node dysfunction. J Thorac Cardiovasc Surg. 2000;120:891-900.

10. Forbess JM, Visconti KJ, Bellinger DC, Jonas RA. Neurodevelopmental outcomes in children after the Fontan operation. Circulation. 2001; 104(12 Suppl 1):I127-32.

11. Wernovsky G, Stiles KM, Gauvreau K, Gentles TL, duPlessis AJ, Bellinger DC, et al. Cognitive development after the Fontan operation. Circulation. 2000;102:883-9.

12. Mahle WT, Clancy RR, Moss EM, Gerdes M, Jobes DR, Wernovsky G. Neurodevelopmental outcome and lifestyle assessment in school-aged and adolescent children with hypoplastic left heart syndrome. Pediatrics. 2000;105:1082-9. 


\section{Discussion}

Dr William G. Williams (Toronto, Ontario, Canada). I appreciate the opportunity to discuss this excellent paper and congratulate Dr Mitchell on his presentation.

You have focused our attention on the need for changing the end points of clinical research from mortality and morbidity to the important area of evaluating general health, well-being, and psychosocial assessment. It's a compliment to our specialty that improving survival with decreasing morbidity has reached the point that these binary end points are now less sensitive indicators of success.

The end points of mortality and morbidity are easily analyzed because they're irrefutable and binary. Death either does or does not occur. Survival is portrayed in time-related graphs, as you have illustrated.

Survival, and survival free of complications, is obviously essential to our patients and their families. But beyond this essential first step, parents will want some idea of the wellbeing of their child and the capability to function within society. Therefore, your attempt at parental assessment of their child's health, school performance, and functional status is an important step into a new area of assessment-new, at least, for surgeons. The clinical end points are no longer binary and irrefutable, but qualitative.

Outcome variables such as general health perception are sometimes referred to as "warm and fuzzy" and the research process as "touchy-feely." These end points are qualitative and meaningful only when compared with a known standard, such as a population of normal children.

By way of example, you state that parents' perception of their child's health is excellent or good in 95\%, yet more than half of the children were hospitalized at some time after the Fontan. Surely this assessment is relative to the time when their child was hospitalized. What is missing in your study is a reference point.

Another example is the school performance, where roughly a third was average, a third above average, and a third below. Surely this is the distribution of any school class. And the important reference point of how these children compared to a normal population would be of great interest.
There are tools to assist us in the qualitative assessment of outcomes, and they are referred to as instruments. These are not the instruments you and I are familiar with in the operating room; they are carefully constructed questionnaires, such as the Child Health Questionnaire or the PedsQL, that have been tested in populations of children with and without acute or chronic disease. These validated questionnaires provide a baseline for comparison, and they have been translated into other languages so that bias from different ethnicities is limited. These reference points to control data might have allowed better correlations with your clinical data, such as circulation arrest times.

To be critical of your methods, your assessment is based upon a customized questionnaire. Did you consider using any of the established validated questionnaires? And you also imply that this study will be continuing and with additional assessments. Will that include a validated questionnaire by the child and by the caregiver?

An important finding in your study is that the population of children with hypoplastic left heart, which constituted $53 \%$ of the total, fared as well as the rest of the single-ventricle population. That is a tribute to the progress in treating these very sick infants that has been led by the Philadelphia group.

Congratulations on a fine contribution and for leading the way towards assessment of functional outcomes.

Dr Mitchell. I have to say I agree with essentially everything that you present there, and you pointed out exactly the limitations of this study. When we designed this study, we designed it as a preliminary study, and so we decided not to use validated questionnaires. We are proceeding with the validations in terms of gathering the physiologic data that may or may not corroborate them, but, in the interim, we hold the view that the parental assessment is in and of itself an important outcome variable.

We do have data that corroborate some of these findings, but they remain to be statistically analyzed now, and, hopefully, that analysis, combined with the neurodevelopmental and IQ testing and electrophysiologic data, will serve to answer these questions. 